\title{
Work Barriers in the Context of Pathways to the Employment of Welfare-to-Work Clients
}

\author{
Shawna J. Lee $\cdot$ Amiram D. Vinokur
}

Published online: 2 October 2007

(C) Springer Science+Business Media, LLC 2007

\begin{abstract}
The ability of welfare-to-work clients to leave the welfare rolls and stay in the labor force is often limited by the work barriers they face. Using a sample of 1,404 female welfare-to-work clients we first examined the structure of work barriers and then tested their contribution to current work status in the context of a structural equation model that incorporated other central pathways to employment. Whereas work barriers included diverse factors ranging from lack of transportation to low quality jobs, they were shown to constitute a uni-dimensional construct. Furthermore, work barriers had a net adverse effect on employment outcomes, controlling for job search self-efficacy and employment intention. We conclude with discussion of implications for the development of
\end{abstract}

This paper is based on research supported by the National Institute of Mental Health grant number P30-MH38330 to the Michigan Prevention Research Center. The first author was supported in part by National Institute of Mental Health Michigan grant number T32-MH63057. The first author presented portions of this paper at the 2005 annual meeting of the International Society for Quality-of-Life Studies (ISQOLS), Philadelphia, PA, and at the 2004 annual meeting of the Society for Social Work and Research (SSWR), New Orleans, LA.

\section{S. J. Lee}

Wayne State University, Detroit, MI, USA

S. J. Lee $(\square)$

School of Social Work, Wayne State University

, 4756 Cass Avenue, Detroit, MI 48201, USA

e-mail: shawnal@wayne.edu

\section{A. D. Vinokur}

Institute for Social Research, University of Michigan, 426 Thompson Street, Ann Arbor, MI 48106, USA

e-mail: avinokur@umich.edu welfare-to-work programs and interventions that target low-income women.

Keywords Welfare - Work - Low-income women . Work barriers · Path model

The 1996 Personal Responsibility and Work Opportunity Reconciliation Act (PRWORA) welfare reform legislation replaced the federal entitlement program with a block grant to individual states, and established a 5-year time limit on receipt of welfare benefits. Prior to 1996, welfare had provided a social safety net to recipients who were mostly single mothers with children. Current federal law requires $30 \mathrm{~h}$ of work per week, or $20 \mathrm{~h}$ for women with children under age 6 , and $10 \mathrm{~h}$ of education, other training, volunteer or community service programs may count toward the work requirement (Haskins and Offner 2003). A dramatic decline in welfare caseloads, from approximately 4 million to 2 million families in the first 5 years following welfare reform, corresponded with a large increase in workforce participation among current and former welfare recipients (Blank 2002; Lichter and Jayakody 2002).

Yet, despite the increase in employment among lowincome women following welfare reform, many current and former welfare recipients face difficulty in transitioning successfully to the workforce and even those who obtain jobs often return to welfare. Job instability is common (Johnson and Corcoran 2003; Lee 2004), and of those who left welfare between 1997 and 1999, 22\% returned to the welfare rolls by 1999 (Loprest 2002a). Barriers that hinder the transition from welfare to work are one reason that some women have difficulty obtaining and maintaining employment, and return to the welfare rolls (Danziger et al. 2000; Taylor 2001; Taylor and Barusch 2004). For 
example, the low quality of jobs in terms of the pay and benefits are often a barrier to employment (Johnson and Corcoran 2003; Lee 2004). Low wage jobs that do not offer health care benefits may contribute to job instability and increase the likelihood that women will return to welfare (Johnson and Corcoran 2003; Lee 2004; Nam 2005). Even with years of work experience, research suggests that many former welfare recipients do not attain jobs with wages above the official U.S. poverty level (Danziger and Johnson 2005; Loprest and Zedlewski 2006).

Beyond the quality of jobs in terms of pay and benefits, inadequate human capital characteristics comprise another set of barriers to work. In one panel study using a representative sample of current and former welfare recipients, $31.4 \%$ reported not having a high school diploma, $15.4 \%$ had limited work experience, and $21.2 \%$ had few job skills (Danziger et al. 2000). Mental and physical health problems pose additional challenges. At some time during the first 4.5 years the study was conducted over $70 \%$ of the respondents reported limited physical functioning and $60 \%$ met the criteria for a mental health disabling condition such as generalized anxiety disorder or severe depression (Corcoran et al. 2003). Additionally, 31\% reported lack of adequate and affordable childcare (Danziger et al. 2004) and $47.1 \%$ said that lack of transportation was a barrier to work (Danziger et al. 2000).

Work barriers are strongly associated with employment. Women with more barriers work less over time and have more difficulty sustaining employment (Corcoran et al. 2003; Danziger et al. 2000, Loprest and Zedlewski 2006). In one study using data from the National Survey of America's Families, $14.1 \%$ of the women had two or more barriers to work; and they were much less likely to be working while receiving welfare compared to those who reported no barriers to work, approximately half of the sample (Zedlewski 2003). Low education, limited work experience, few job skills, and poor mental and physical health decrease job retention and increase the likelihood that a former recipient will return to welfare (Corcoran et al. 2000; Loprest 2002b; Nam 2005). Those with a work history in which they have been on welfare (or have not worked) for an extended period of time are more likely to return to welfare (Loprest 2002b).

In addition to the work barriers mentioned above that reduce the likelihood and extent of employment among low-income women, some studies have examined additional work barriers such as learning disabilities, perceived discrimination, drug dependence, child health problems, substance abuse problems, and domestic violence (e.g., Danziger et al. 2000; Dooley and Prause 2002; Gutman et al. 2003; Nam 2005; Taylor 2001; Taylor and Barusch 2004; Pollack et al. 2002; Zedlewski 2003). To date, measurement of work barriers has not been conceptualized in a coherent manner and researchers have not asked if there is a cohesive structure underlying factors related to work barriers. While one study noted the high internal consistency of a work barriers measure (Taylor 2001), most often work barriers are treated as distinct variables or summed to create a composite score. Thus, there remains a question of whether these barriers constitute discrete and unique factors or whether they are indicators of a global uni-dimensional construct that impedes employment.

To address this gap in the literature regarding the conceptualization of work barriers, the first goal of the current study is to examine the underlying structure of diverse work barriers that in past literature have been examined separately as predictors of employment. We focus on those barriers that are most common and have demonstrated a relationship to employment outcomes, including: inadequate human capital (education and job experience), inadequate job quality in terms of pay and health benefits, childcare, lack of transportation, and depression. Establishing that a diverse set of work barriers form a unidimensional construct is an important step in demonstrating the predictive validity of the construct particularly if, as we expect, work barriers predict future low level of employment or unemployment.

The second goal of this study is to examine the extent to which the work barrier construct predicts future employment engagement among welfare-to-work clients. Support for negative consequences of the work barrier construct on employment outcomes would substantiate the theoretical validity of the barrier construct particularly if it is obtained within a broader network of constructs that are tied to employment.

We also seek to expand knowledge related to work barriers by measuring barriers in a manner that diverges from previous research. In past research work barrier variables have been constructed based on respondent's demographic and other characteristics; for example, the absence of a high school diploma as an indicator of an education work barrier. Instead, this study focuses on the perception of work barriers by asking participants to indicate to what extent factors such as not having enough education and work experience prevented them from looking for or getting a job. In this way we extend previous research by examining if the belief that one has work barriers influences the intention to participate in the job search and gain employment in the same way that job search self-efficacy is found to influence intention, though in the opposite direction (e.g., van Ryn and Vinokur 1992). The objective aspects of work barriers may cause them to be highly interrelated. For example, low education may hinder the ability to obtain an adequately paying job, which in turn creates financial problems linked to childcare and transportation. At the same time, the perception that these 
factors act as barriers to work creates a psychological motivational force akin to, but in the opposite direction of, job search self-efficacy or mastery by inhibiting either the intention to gain employment or effective behavior that could lead to positive work outcomes.

\section{Structural Model of Pathways to Employment}

In order to assess the extent to which the work barrier construct predicts employment we constructed a model to predict employment experience. This model is based on earlier studies with unemployed job seekers (Vinokur and Schul 1997, 2002; Vinokur et al. 2000) that have demonstrated direct and mediating relationships among mastery, financial strain, job search self-efficacy, and employment intention to employment. In studies using both community samples and intervention participants, higher levels of mastery were positively related to job search self-efficacy, reduced financial strain, and lowered depressive symptoms; these mediators in turn increased job search intention and are related to more positive employment outcomes over time (Vinokur and Schul 1997, 2002; Vuori and Vinokur 2005). In the current study, it is additionally hypothesized that the work barrier construct hinders employment. Specific hypotheses are examined in more detail below.

Following from the model of human agency proposed by Bandura (1989), motivation and intention to act is enhanced when individuals have a belief in their ability to exercise control over their environment. High levels of mastery can promote positive, proactive coping strategies in the face of difficult life circumstances, thereby reducing vulnerability to depression and other negative psychological outcomes (Elder and Russell 2000; Conger et al. 2000; Conger et al. 1999; Vinokur et al. 2000). When those with lower levels of mastery encounter difficult life circumstances their sense of mastery is further eroded, increasing emotional distress and symptoms of depression (Conger et al. 1999).

Mastery is believed to be central to, but distinct from, self-efficacy. Self-efficacy is a feeling of competency in a particular domain that is derived from a sense of control over one's environment in that domain, and is believed to emanate in part from a broader sense of mastery. Therefore, to isolate the effect of self-efficacy that is specific to the job domain we conceptualized mastery as a more general variable influencing self-efficacy as well as financial strain, employment intention, and work barriers. It is only when known predictors of employment are controlled for that the net effects of a work barrier construct can be demonstrated with appropriate rigor.

Consistent with the notion of mastery as a general variable, and as shown in previous research (Vinokur and
Schul 1997, 2002), the effect of mastery on employment experience is not a direct one but is mediated by more proximal variables related to employment. In our model we include financial strain as a mediator. Previous research with middle-class samples has shown that mastery reduces financial strain (Vinokur and Schul 2002). Financial strain may also increase the intention to seek a job due to the need for income, while work barriers may discourage and dampen the intention to become employed. Assessing the impact of financial strain in the context of work barriers is important because although employment may be beneficial to low-income mothers (Raver 2003), it does not necessarily reduce financial strain due to the low quality of employment and other factors (Danziger and Kalil 2002; Gyamfi et al. 2001; Jackson et al. 2000). Furthermore, in a low-income sample, financial strain is indicative of shortage of financial resources that could have otherwise been deployed to diminish or remove work barriers (Vinokur and Schul 1997, 2002).

The model includes three direct predictors of employment experience: work barriers, job search self-efficacy, and employment intention. Mastery according to the model is hypothesized to have a direct impact on job search selfefficacy, employment intention (Vinokur and Schul 1997, 2002) as well as on work barriers, which in turn influence employment experience.

As noted above, previous research with low-income women and welfare recipients has also established that work barriers are impediments to obtaining and maintaining employment (Danziger et al. 2000; Danziger et al. 2004; Johnson and Corcoran 2003; Taylor and Barusch 2004; Zedlewski 2003), whereas positive psychological mechanisms, including self-efficacy, are related to lowered reliance on welfare, positive employment outcomes, and well-being (Danziger et al. 2001; Kalil et al. 2001; Kunz and Kalil 1999). In several cross-sectional studies of lowincome mothers who were working or on welfare, selfefficacy was positively correlated with employment (Jackson 2000; Jackson and Scheines 2005). Following from this research it is hypothesized that barriers to work form another mediator in the relationship between mastery and women's employment outcomes, and that mastery decreases perceived work barriers.

Job search self-efficacy is also hypothesized to have a direct effect on employment and mediate the relationship between mastery and employment outcomes. Multiple studies suggest that domain specific self-efficacy increases the likelihood that one will successfully initiate behavior in a particular domain (Bandura and Cervone 1983; Bandura 1989; Conger et al. 1999; Elder and Russell 2000). When individuals feel efficacious and competent they are able to take on challenges and are more likely to persist even in the face of failure (Bandura 1989). Job search self-efficacy is 
therefore likely to increase intention to seek and find a job as well as directly improve employment outcomes (van Ryn and Vinokur, 1992).

According to the theory of planned behavior, intention is the direct predictor of future behavior (Ajzen 2002) and behavior is in turn a predictor for relevant outcomes, such as in our case, employment. In the absence of a measure of job search behavior we hypothesize that intention is a direct predictor of employment experience. We also hypothesize that employment intention is increased by job search self-efficacy and financial strain, and is decreased by work barriers. Employment experience is increased by job search self-efficacy and employment intention, in addition to being negatively influenced by work barriers as discussed above.

To investigate the question of whether work barriers constitute a valid construct, and to test our model based on the hypotheses stated above, which also incorporated work barriers, we used data collected from female welfare-towork clients in a job training program. Our analyses will first examine the structure of work barriers and then proceed to test a structural model predicting employment experience.

\section{Method}

\section{Participants}

Study participants were 1,404 female welfare applicants in an urban southeastern county who took part in the Winning New Jobs (WNJ) job preparation program to qualify for welfare benefits. ${ }^{1}$ Participation in the study was completely voluntary. The mean age of participants was 29.27 (SD = 7.91) years old. In terms of education, $37 \%$ have not completed high-school education, $39.4 \%$ were high-school graduates, $21 \%$ had attended some college, and only $2 \%$ reporting either a college degree or graduate degree. Most of the participants (62\%) were African-Americans; $30 \%$ were Caucasian/whites; and $6.6 \%$ were of bi-racial, Asians, Native Americans or others of unspecified racial background.

The majority of participants indicated their marital status as never married $(65 \%)$. Only $6.1 \%$ were married, $15.6 \%$ were separated, $10.5 \%$ were divorced, and $1 \%$ of the participants were widowed. Participants had an average of $1.96(\mathrm{SD}=1.15$, median $=2)$ children. Over $96 \%$ of the participants had children; $37 \%$ had one child, $32 \%$ had two

\footnotetext{
1 The original sample included additional 139 male applicants. Because of their small number and the fact that females face unique challenges in the transition from welfare-to-work, our analyses included only the female participants.
}

children, $16.6 \%$ had three children, and almost $10 \%$ had four or more children. Furthermore, many had young children under age 5 at home: $40 \%$ had one young child at home, $17.5 \%$ had two young children at home, and $4.7 \%$ had three or more young children at home.

\section{Procedure}

From September 2000 to September 2002 all individuals applying for welfare benefits and who participated in WNJ were recruited to the study. They were asked to complete a self-administered questionnaire at the beginning of the WNJ workshop. Of the 1,597 women who applied to the welfare cash assistance program and thus were required to participate in WNJ in order to receive benefits, 1,404 showed up to the workshop and provided Time 1 (T1) baseline data (193 women never showed up to participate in the program). Four months after completing the WNJ workshop participants were re-contacted (Time 2, or T2) and asked to participate in a telephone interview. Of the 1,404 who participated at T1, $951(68 \%)$ women provided T2 follow-up data. The participants were paid $\$ 5$ for completing the $\mathrm{T} 1$ baseline questionnaire and $\$ 10$ for completing the $\mathrm{T} 2$ follow-up telephone interview.

\section{Measures}

Sense of Mastery (Perlin and Schooler 1978) measure $(\alpha=.72, M=3.01, \mathrm{SD}=.52)$ consisted of seven questions that asked respondents to rate their sense of personal control over aspects of their life, with response options ranging from 1 (strongly disagree) to 4 (strongly agree). Questions included: "There is really no way I can solve some of the problems I have"; "Sometimes I feel I am being pushed around in life"; "I have little control over the things that happen to me"; "I can do just about anything I really set my mind to do"; "I often feel helpless in dealing with the problems of life"; "What happens in the future mostly depends on me," and "There is little I can do to change many of the important things in my life." In our model this construct was indicated with two parcels formed by the means of the randomized sets of three or four items in each parcel. Parceling items to form indicators is a common procedure in structural modeling analysis because it results in parcel indicators with more appropriate distributional properties in terms of multivariate normality (see, Bandalos 2002; Kline 2005).

Job Search Self-Efficacy was assessed with a measure used in earlier investigations on job search and employment (e.g., Vinokur and Schul 2002). The measure $(\alpha=.93, M=3.90, \mathrm{SD}=1.02)$ consisted of six questions 
asking respondents to rate on a five-point scale from 1 (not at all confident) to 5 (a great deal confident) their degree of confidence in being able to successfully perform six job search activities: making a good list of all the skills that you have and can be used to find a job; talking to friends and other contacts to find out about potential employers who need your skills; talking to friends and other contacts to discover promising job openings that are suitable for you; completing a good job application and resume; contacting and persuading potential employers to consider you for a job; and making the best impression and getting your points across in a job interview. In our modeling analysis the indicators for this construct were formed by two parcels using the means of the randomized sets of three items in each parcel.

Financial Strain measure $(\alpha=.76, \quad M=3.57, \quad \mathrm{SD}=$ 1.02) was constructed from answers to three questions used in earlier investigations on job search and employment (e.g., Vinokur and Caplan 1987). Respondents indicated how difficult it was for them to live on their total household income using a scale from 1 (not at all difficult) to 5 (extremely difficult or impossible). Respondents then rated the likelihood of experiencing financial hardships and of having to live with only bare necessities in the next 2 months on a scale from 1 (not at all) to 5 (a great deal). The three items served as indicators for the financial strain construct.

Employment Intention measure $(\alpha=.65, \quad M=4.25$, $\mathrm{SD}=1.02$ ) was also used in earlier studies on reemployment (Vinokur and Caplan 1987; Vinokur and Schul 2002). On a scale from 1 (not at all hard/very unlikely) to 5 (extremely hard/very likely) respondents were asked two questions: "In the next 2 months, how hard do you intend to try to find a job where you'd work $20 \mathrm{~h}$ or more per week?" and "In the next 2 months, how likely is it that you will try hard to get a job where you'd work $20 \mathrm{~h}$ or more per week?" These two items served as indicators for the employment intention construct in the modeling analysis.

Work Barriers were assessed using five indicator measures: depressive symptoms, inadequate human capital, inadequate job quality, childcare problems, and transportation problems. Below is a description of each of these measures.

Hopkins Depression Symptom Checklist (HSCL; a measure based on Derogatis et al. 1974; $\alpha=.92, M=2.66$, $\mathrm{SD}=1.09$ ) was used to assess symptoms of depression. On a response scale ranging from 1 (not at all) to 5 (extremely), respondents rated the extent to which they were bothered or distressed by each of eight symptoms in the last 2 weeks, including: poor appetite, feeling low in energy or slowed down, feeling hopeless about the future, crying easily, blaming yourself for things, feeling lonely, feeling no interest in things, and feeling blue. This scale was used in previous studies of job search and employment (Caplan et al. 1989; Vinokur and Schul 2002) and has been found effective in identifying individuals who are at risk of meeting clinical criteria for depression (Sandanger et al. 1998). The depressive symptoms construct was indicated by three parcels that were constructed based on the mean scores of randomly chosen subsets of two or three items from the HSCL symptom checklist.

The other four work barrier domains in this study were based on barriers identified in WES (Danziger et al. 2000), a longitudinal panel study of current and former welfare recipients in urban Michigan that examined work barriers and employment outcomes following welfare reform. However, wording of the work barrier questions used in this study differed from WES. In WES, barriers were constructed based on objective indicators such as selfreported educational level. Our measures asked for respondents' perception of the extent to which various factors acted as a barrier to looking for or getting a job. Participants rated on a five-point scale ranging from 1 (not at all) to 5 (a great deal) "How much does each of the following things prevent you from looking for a job or from getting a job?" Inadequate human capital was assessed by two ratings in response to "not having enough education" and "not having enough job experience". Inadequate job quality was assessed by the two ratings in response to "jobs with too little pay" and "jobs without health benefits". Childcare related barrier was assessed by two ratings in response to "cost/availability of childcare" and "wanting/needing to stay home with your children". Finally, difficulties with transportation were assessed by the rating in response to "having transportation problems". For our initial confirmatory factor analysis of work barriers, each of the items served as an indicator of the respective latent construct. In the final model to predict employment experience, the means of the items for each type of barrier were indicators for the respective barrier, with a total of five indicators for the latent factor of work barriers.

Work Experience (Employment) was measured at T2, 4 months after $\mathrm{T} 1$ baseline data collection. Respondents reported whether they are working for pay or not, and, if working, the number of hours per week they worked for pay. The analyses below focus on the following dependent variables of employment (1) dichotomous work variable coded 0 for reports of not working at all and 1 for reports of working any number of hours (Fig. 2), (2) dichotomous work variable coded 0 for reports of not working or working up to $19 \mathrm{~h}$ per week and 1 for reports of working 20 or more hours per week, and (3) work variable based on the reported number of hours working for pay per week (including 0 for not working). 
Although approximately 450 of the original WNJ participants either declined to participate or could not be located at the T2 4-month follow-up, analyses revealed that T2 participants and non-participants did not differ on most variables, including race, education attainment, marital status, number of children, children under age 5 at home, employment intention, job search self-efficacy, mastery, and the work barriers (depression, quality of jobs, human capital, kids transportation). However, participants who failed to complete the T2 follow-up were slightly younger $(M=28.36, \mathrm{SD}=7.47)$ than those that did complete the follow-up $(M=29.70, \mathrm{SD}=8.09)(t$ $(1,401)=-2.98, p<.01)$. This difference is very small and may have little practical significance. T2 participants also differed with respect to financial strain: those who did not complete the follow-up survey had lower levels of financial strain than those that did complete the follow-up $(M=3.35,3.48$, respectively, $t(1,395)=-2.54, p<.05)$, and again, while the difference is statistically significant, it is small.

\section{Results}

\section{Descriptive Results}

Table 1 displays the correlation matrix, means, and standards deviations of demographic variables and variables used in both models displayed in Figs. 1 and 2. For the most part, as expected, desirable attributes (e.g., mastery, job search self-efficacy, and employment intention) were negatively correlated with financial strain and work barriers. The various work barriers were positively correlated.

\section{Overview of the Analytic Procedures}

Models were tested by a confirmatory latent-variable structural analysis using EQS version 6.1 (Bentler 2005). Analyses were based on maximum likelihood procedure applied to listwise covariance matrices. In accordance with guidelines for reporting structural equation modeling results (Boomsma 2000; Raykov et al. 1991) we report the following goodness-of-fit measures: normed fit index (NFI), nonnormed fit index (NNFI), comparative fit index (CFI), and the misfit measure known as the root-mean square error of approximation (RMSEA). NFI, NNFI, and CFI fit indices that exceed .90 indicate that the data provide acceptable fit for the model (Raykov et al. 1991). Goodness of fit indices that meet or exceed .95 and a RMSEA index at or below .06 are indicative of good fit $(\mathrm{Hu}$ and Bentler 1999).
Model 1. Do Work Barriers Constitute a Unidimensional Factor?

We tested a confirmatory factor model of work barriers with one second-order factor of work barriers indicated by five first-order factors that represented the five types of work barriers (i.e., human capital, quality of jobs, childcare, transportation, and depression). The results of the final model are presented in Fig. 1. The results for the estimation of the work barrier model demonstrate acceptable fit with $\chi^{2}(d f=32, N=1,250)=63.67$; NFI $=.986$; NNFI $=.990 ;$ CFI $=.993 ;$ RMSEA $=.028$. These results highlight a coherent underlying structure to work barriers even as these factors represent unique types of work barriers.

Model 2. Pathways to Employment: Does the Work

Barrier Construct Predict Negative Employment

Experience?

Next we tested a structural model for predicting employment experience at T2 4 months following participation in WNJ. Employment experience was analyzed using a dichotomous dependent variable indicating if respondents were not working at all (coded 0$)$ or working 1 or more hours per month (coded 1$) ; 43 \%$ of respondents $(N=539)$ were not working at all, and $57 \%$ were working between 1 and $75 \mathrm{~h}$ per week $(M=33.64, \mathrm{SD}=10.72)$. Because of the inclusion of this dichotomous variable the model was estimated using a maximum likelihood with robust procedure in order to obtain the Sattora-Bentler corrected $\chi^{2}(\mathrm{~S}-$ $\left.\mathrm{B} \chi^{2}\right)$ as well as the corrected standard errors for the parameters (see, Bentler 2005). The model included one observed (i.e., measured) variable, work experience, and five latent factors with their respective indicators (see, Section on Measures), with the relevant paths of influence explained by the study hypotheses. The work barrier factor was developed based on Model 1. Each work barrier was indicated by the mean score of the relevant items, resulting in the five work barriers indicators described in the measurement section (depressive symptoms, inadequate human capital, inadequate job quality, childcare problems, and transportation problems). In Model 2 we reduced the number of individual indicators for each barrier to attain greater parsimony while maintaining the theoretical relevance of the work barriers construct. The model and results are presented in Fig. 2.

Prior to testing the structural model we estimated its underlying measurement model. The results for the measurement model demonstrated acceptable fit with $\chi^{2}$ $(d f=76, \quad N=846)=241.84 ; \quad$ NFI $=.93 ; \quad$ NNFI $=.93$; $\mathrm{CFI}=.95 ; \mathrm{RMSEA}=.050$. The estimation results for the 
Table 1 Correlation matrix

\begin{tabular}{|c|c|c|c|c|c|c|c|c|c|c|c|c|c|c|c|}
\hline Study variable & 1. & 2. & 3. & 4. & 5. & 6. & 7. & 8. & 9. & 10. & 11. & 12. & 13. & 14. & 15. \\
\hline 1. Age & - & & & & & & & & & & & & & & \\
\hline 2. Education ${ }^{\mathrm{a}}$ & .19 & - & & & & & & & & & & & & & \\
\hline 3. Race $^{\mathrm{b}}$ & -.08 & .13 & - & & & & & & & & & & & & \\
\hline 4. Mastery & -.04 & .13 & .20 & - & & & & & & & & & & & \\
\hline 5. Job search self-efficacy & .07 & .19 & .16 & .38 & - & & & & & & & & & & \\
\hline 6. Financial strain & .20 & .18 & -.13 & -.18 & .09 & - & & & & & & & & & \\
\hline 7. Employment intention & .01 & .15 & .02 & .15 & .32 & .18 & - & & & & & & & & \\
\hline 8. Mean score of all work barriers & -.00 & -.11 & -.18 & -.35 & -.11 & .31 & .05 & - & & & & & & & \\
\hline 9. Human capital work barrier & -.08 & -.34 & -.09 & -.19 & -.17 & .07 & -.02 & .57 & - & & & & & & \\
\hline 10. Job quality work barrier & .08 & .04 & -.00 & -.08 & .08 & .16 & .09 & .60 & .19 & - & & & & & \\
\hline 11. Childcare work barrier & -.23 & -.04 & -.13 & -.13 & -.07 & .08 & .03 & .57 & .17 & .20 & - & & & & \\
\hline 12. Transportation work barrier & .12 & -.00 & -.12 & -.26 & -.07 & .20 & .00 & .59 & .11 & .13 & .09 & - & & & \\
\hline 13. Depression work barrier & .08 & .04 & -.20 & -.40 & -.13 & .44 & .05 & .66 & .20 & .19 & .19 & .48 & - & & \\
\hline 14. Employment at $\mathrm{T} 2$ & -.01 & .12 & .06 & .11 & .14 & -.01 & .12 & -.04 & -.02 & .08 & -.04 & -.06 & -.09 & - & \\
\hline 15. Hours worked per week & -.02 & .16 & .05 & .13 & .14 & .01 & .14 & -.05 & -.06 & .06 & -.05 & -.05 & -.07 & .92 & - \\
\hline$M$ & 29.27 & 1.88 & 1.76 & 3.02 & 3.91 & 3.44 & 4.25 & 2.63 & 2.58 & 3.19 & 2.96 & 1.77 & 2.66 & .43 & 14.51 \\
\hline SD & 7.91 & .80 & .56 & .52 & 1.03 & .94 & 1.02 & .73 & 1.24 & 1.30 & 1.32 & 1.18 & 1.09 & .50 & 18.09 \\
\hline
\end{tabular}

$* p<.05, * * p<.01$

Note: All the correlations that are equal or larger than .07 are statistically significant at the .05 level. Higher scores correspond with higher variable levels on all variables

${ }^{a}$ Education: 1 = less than high school, 2 = high school graduate, $3=$ some college, $4=$ college or post-college graduate

${ }^{\mathrm{b}}$ Race: 1 = Caucasian/white, 2 = African-American and other minorities

${ }^{c}$ Employment at T2: $0=$ not working, 1 = working

structural model also provided acceptable fit with $\mathrm{S}-\mathrm{B} \chi^{2}$ $(d f=80, \quad N=846)=281.42 ; \quad \mathrm{NFI}=.92 ; \quad \mathrm{NNFI}=.92 ;$ $\mathrm{CFI}=.94$; RMSEA $=.055$. Because of the potential for bias due to considerable attrition at T2 posttest, we conducted an analysis using EM imputation procedure available in EQS software and estimated the model in Fig. 2 with a fully imputed data set. The results demonstrated that the data provided slightly better fit to the model than the non-imputed data set. The $\mathrm{S}-\mathrm{B} \chi^{2}$ (81, $N=1,404)=384.02$ with NFI and NNFI $=.93, \mathrm{CFI}=.94$, and RMSEA $=.050$ [.046 .057]. Most importantly, the size of the beta coefficients of the paths in the model remained virtually the same as well as the coefficients' level of statistical significance (or non-significance for the path from job search efficacy to work).

Although it is more parsimonious to report results using either "working" or "not working" as the outcome variable, we tested two additional models with different work experience outcomes. Given that many low-income women are employed in jobs that do not have steady, consistent weekly hours, it was important to use several different employment outcome variables to demonstrate that the model results were not sensitive to small changes in the outcome variable. Alternative models were tested using: a dichotomized variable with those not working or working fewer than $20 \mathrm{~h}$ per week (coded 0 ) versus working at least $20 \mathrm{~h}$ per week (coded 1); then once more by the reported number of hours working per week. The 20-h rate is consistent with the federal welfare work requirements policies that require recipients to work, do community service, or participate in education for $20 \mathrm{~h}$ a week. For the dichotomous variable, $61 \%$ of respondents were not working or working fewer than $20 \mathrm{~h}$ per week. For the continuous variable reflecting number of hours worked per week, participants worked an average of $33.64 \mathrm{~h}(\mathrm{SD}=10.72)$. The results for the estimation of the two models demonstrated equally good fit and nearly the same path coefficients. The results for the former model were $\mathrm{S}-\mathrm{B} \chi^{2}$ $(d f=80, \quad N=846)=278.61 ; \quad \mathrm{NFI}=.92 ; \quad \mathrm{NNFI}=.92 ;$ $\mathrm{CFI}=.94 ; \mathrm{RMSEA}=.054$. The results for the latter model were $\mathrm{S}-\mathrm{B} \chi^{2} \quad(d f=80, \quad N=846)=311.15 ; \quad \mathrm{NFI}=.93$; $\mathrm{NNFI}=.93 ; \mathrm{CFI}=.94 ; \mathrm{RMSEA}=.058$.

In addition to the overall good fit to the data, the model lends support to most of our specific hypotheses (Fig. 2) with statistically significant paths. Only one path, from job search self-efficacy to employment experience, did not attain statistical significance. Another path, from work barriers to employment intention, suggests that work barriers increased the intention to work rather than to decrease it as was originally hypothesized. It seems that the 


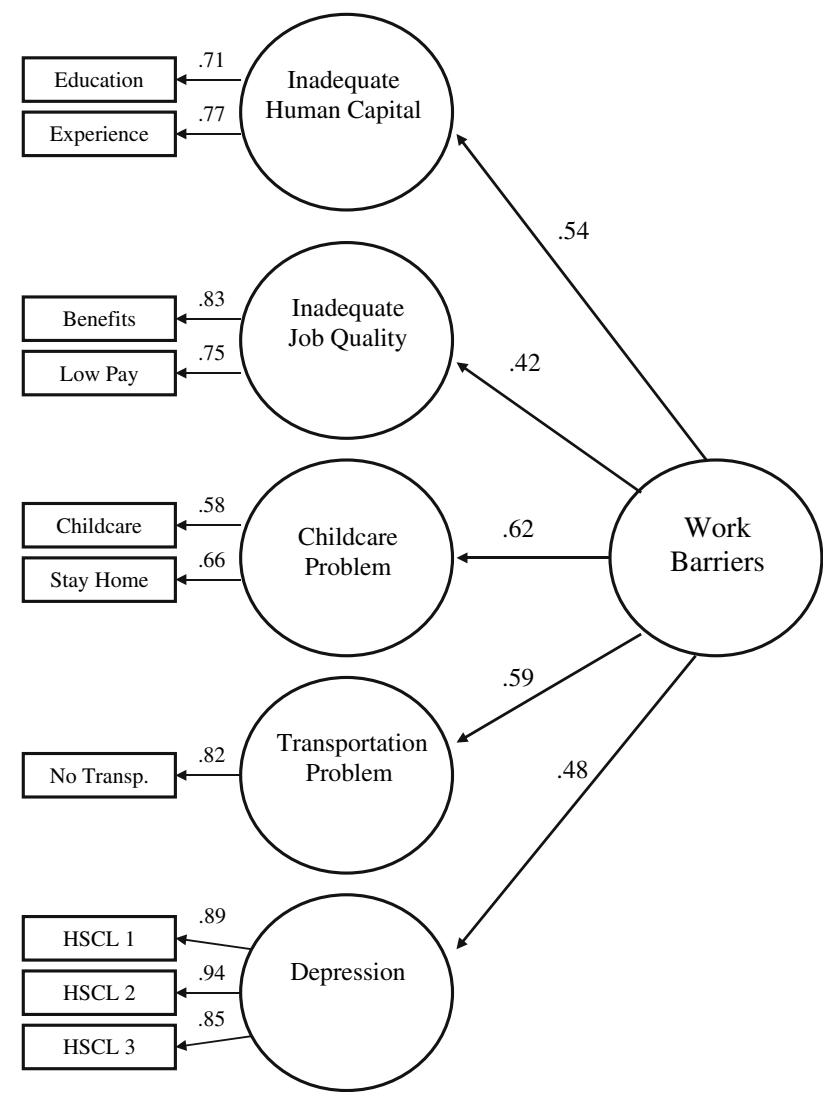

Fig. 1 Uni-dimensional work barrier construct. $\chi^{2} \quad(d f=32$, $N=1,250)=63.67 ; \quad \mathrm{NFI}=.986, \quad \mathrm{NNFI}=.990, \quad \mathrm{CFI}=.993, \quad$ and RMSEA $=.028$

realization of the adversity in the form of barriers serves to increase the intention to seek work for welfare-to-work clients who are mandated to do so while still having a net adverse effect on employment outcomes. Their situation may be analogous to people who need to lose weight and face obstacles or barriers to engage in weight loss behavior. It would be reasonable to hypothesize that they would form stronger intentions exactly because of their need to lose weight than their counterparts who do not have to lose weight as urgently.
Both mastery and financial strain were shown to have a strong impact on work barriers. While sense of mastery decreased perceived barriers $(\beta=-.49)$, financial strain increased perceived barriers $(\beta=.46)$. Despite the positive effect of work barriers on intention $(\beta=.21)$, work barriers had a negative impact on work experience $(\beta=-.11)$. Whereas work barriers bring good intentions, they produce poor employment outcomes as also shown in past research (Corcoran et al. 2003; Zedlewski 2003).

The remaining pathways to work experience were quite similar to those shown in research using large and diversified community samples of unemployed job seekers (e.g., Vinokur and Schul 2002). Sense of mastery increased employment intention, job search self-efficacy, and decreased financial strain $\left(\beta_{\mathrm{s}}=.31, .45\right.$ and.-19 , respectively). Job search self-efficacy and financial strain increased employment intentions $\left(\beta_{\mathrm{s}}=.28, \quad .14\right.$ respectively).

\section{Discussion}

While it is known that barriers to work are negatively associated with women's employment (Corcoran et al. 2000; Danziger et al. 2000; Nam 2005; Zedlewski 2003), little is known about the pathways by which barriers hinder employment. Relatively few studies examining the employment of women on welfare include personal resiliency variables such as mastery and self-efficacy (exceptions include Danziger et al. 2001; Jackson 2000; Jackson and Scheines 2005; Kalil et al. 2001). Studies investigating the effects of barriers on employment rarely control for personal resource factors such as financial strain, mastery, and self-efficacy (e.g., Nam 2005; Taylor and Barusch 2004), nor do most studies examine respondents' perceived work barriers. This study addresses these gaps in the literature and makes a unique contribution by examining pathways to employment, including resiliency factors, among low-income women.
Fig. 2 Structural model of pathways to employment among low-income women. S-B $\chi^{2}$ $(d f=80, N=846)=281.42$, $\mathrm{NFI}=.92, \mathrm{NNFI}=.92$, $\mathrm{CFI}=.94$, and RMSEA $=.055$. Paths are shown with the standardized coefficients $\left(\beta_{\mathrm{s}}\right)$, all significant at $p<.05$, with the exception of the indicated pathway from job search selfefficacy to work

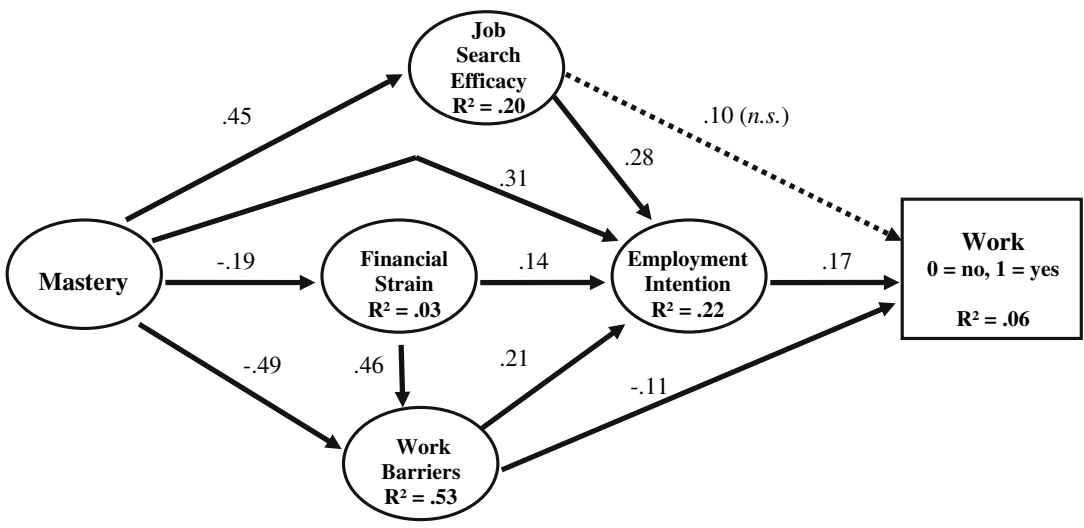


We first examined the underlying structure of work barriers and then tested their contribution to work experience in the context of a structural equation model that incorporated other central pathways to employment. Results demonstrated that a diverse set of impediments to getting or holding a job, including inadequate human capital, inadequate job quality, childcare problems, transportation problems, and depression, were indicators of an underlying uni-dimensional construct that can be conceived of as work barriers. Furthermore, the construct was shown to have a net adverse effect on employment outcomes, controlling for job search self-efficacy and employment intention.

The model offers numerous implications for interventions to reduce the adverse effects of work barriers. Not all women are ready and able to respond to the welfare system's "work-first" mandate-particularly with regards to maintaining employment over time-and welfare clients themselves indicate that they are in need of services to address a broad range of work barriers (Danziger and Seefeldt 2002). This study suggests the need for intervention at multiple levels: many women may benefit from individual supports that promote mastery and self-efficacy in the transition to work and programs that address mental health problems; furthermore, there is clearly the necessity for systems-level programs and policies that direct concrete resources, such as subsidized transportation and childcare, to low-income women. Building from this framework, we discuss two approaches that may be useful in addressing work barriers, particularly when used in conjunction with one another. First, short-term interventions focusing on "soft skills" to promote women's well-being beyond the work-first focus on employment skills (Holzer et al. 2004); and second, policies responsible for the transfer of resources to low-income women.

As it stands now, the welfare-to-work model used in many locations often requires welfare applicants to attend job training or work-first classes that are focused on immediate re-attachment to the labor market. Content often includes traditional job search skills, such as résumé writing or making job contacts. The current study suggests that traditional job training programs that also enhance mastery and job search self-efficacy may improve welfare clients' job readiness by increasing their intention to search for a job, become employed, and stay in the job market.

Such programs have been successfully used in numerous settings with unemployed working- and middle-class individuals (e.g., Caplan et al. 1989; Vuori et al. 2002; Vuori and Vinokur 2005). For example, the Jobs Program (Caplan et al. 1989; Vinokur et al. 1995) was designed as a job-search skill enhancement workshop to promote reemployment among the recently unemployed. However, program activities were designed to increase self-efficacy in the job search and also to inoculate participants against setbacks in the search for new employment (Vinokur and Schul 1997; Vuori and Vinokur 2005).

In a low-income context, this model should be extended to address common work barriers through structured activities intended to reduce some of the adverse effects of work barriers. For example, the learning context could include activities that help women to anticipate those barriers that they are likely to experience while employed, and then activities to facilitate the development of a plan to address the barriers. These activities are likely to bolster confidence in one's ability to deal with work barriers while being employed and contribute to inoculation against setbacks that promote effective behavior change in stressful situations (Meichenbaum 1985). Past research has demonstrated that linking goals with specific goal-directed responses as well as engaging in inoculation against setbacks are effective means to promote goal-directed motivation and implementation of behavioral change in numerous settings (Gollwitzer and Brandstatter 1997; Gollwitzer and Kinney 1989; Gollwitzer 1999), including among the unemployed seeking jobs (Vuori and Vinokur 2005).

A second level of intervention is improved policies and programs that promote work, which have been discussed in detail elsewhere (e.g., Hamilton 2002; Michalopoulos et al. 2000a; Pavetti et al. 1996; Scarpace et al. 2005). Policies that "make work pay," such as income disregards and expanded eligibility for transitional Medicaid, increase women's ability to obtain and sustain employment (e.g., Bos et al. 1999; Michalopoulos et al. 2000b; Miller et al. 2000). Increasing the minimum wage and more job training and educational programs are needed so that working a full-time, minimum wage job pushes poor families out of poverty (Lino 1994).

Perhaps most relevant to the barriers discussed in this study, there is now a substantial literature pointing to the need for expanded subsidized childcare options, such Head Start and public pre-kindergarten programs, and childcare that responds to the employment constraints of low-income earners (e.g., accommodate nonstandard work schedules) (Coley et al. 2001; Lee 2004).

\section{Study Caveats}

Whereas this is the first study to examine the structure of a work barrier construct and pathways connecting work barriers and psychological constructs to employment, it has a number of limitations that should be addressed in future studies. First, we focus on those barriers that are most common among low-income women and thus do not include substance dependence, criminal record, lack of access to services, and physical health problems (e.g., 
Dooley and Prause 2002; Gutman et al. 2003; Taylor 2001). The second limitation of this study results from the fact that the respondents participated in a mandated job preparation program, which may have helped them overcome barriers thus reducing the impact of work barriers on employment in our sample. Finally, the longitudinal aspect of our model only pertains to the measurement of employment outcomes. All other variables were assessed at Time 1, and as such constitute a cross-sectional design where the direction of influence may be the reverse of what appears in our model. For example, work barriers may have a causal influence on financial strain rather than be its outcome as suggested in our model. A more definitive study should include a wider array of measured work barriers and a design with more follow-up periods of all measures using a sample of respondents whose experience is not affected by participation in a program.

\section{Summary of Results}

In this study we expand current knowledge related to lowincome women and work by establishing that perceived work barriers form a uni-dimensional construct and then examining the independent adverse effect of work barriers on employment within multiple other pathways to employment, including personal resiliency factors. Results suggest that welfare programs and policies would better serve clients if they addressed the problems that are commonly experienced by women transitioning from welfare to work. This could be accomplished through development of innovative programs that identify a broad range of barriers to work and serve to improve well-being, as well as comprehensive policies that provide concrete resources to lowincome women.

\section{References}

Ajzen, I. (2002). Perceived behavioral control, self-efficacy, locus of control, and the theory of planned behavior. Journal of Applied Social Psychology, 32, 665-683.

Bandalos, D. L. (2002). The effects of item parceling on Goodness-offit and parameter estimate bias in structural equation modeling. Structural Equation Modeling, 9, 78-102.

Bandura, A. (1989). Human agency in social cognitive theory. American Psychologist, 44, 1175-1184.

Bandura, A., \& Cervone, D. (1983). Self-evaluative and self-efficacy mechanisms governing the motivational effects of goal systems. Journal of Personality and Social Psychology, 45, 1017-1028.

Bentler, P. M. (2005). EQS version 6.1 structural equation program manual. Los Angeles: BMDP Statistical Software.

Blank, R. (2002). Evaluating welfare reform in the United States. Journal of Economic Literature, XL, 1105-1166.

Boomsma, A. (2000). Reporting analyses of covariance structures. Structural Equation Modeling, 7, 461-482.
Bos, J. M., Huston, A. C., Granger, R. C., et al. (1999). New hope for people with low incomes: Two-year results of a program to reduce poverty and reform welfare. New York: MDRC.

Caplan, R. D., Vinokur, A. D., Price, R. H., \& van Ryn, M. (1989). Job-seeking, reemployment and mental health: A randomized field experiment in coping with job loss. Journal of Applied Psychology, 74, 759-769.

Coley, R. L., Chase-Lansdale, P. L., \& Li-Grining, C. P. (2001). Child care in the era of welfare reform: Quality, choices and preferences (welfare, children and families: A three-city study, policy brief 01-4). Baltimore: Johns Hopkins University.

Corcoran, M., Danziger, S. K., Kalil, A., \& Seefeldt, K. S. (2000). How welfare reform is affecting women's work. Annual Review of Sociology, 26, 241-269.

Corcoran, M., Danziger, S. K., \& Tolman, R. (2003). Long term employment of African American and White welfare recipients and the role of persistent health and mental health problems. Women \& Health, 39, 21-32.

Conger, R. D., Conger, K. J., Matthews, L. S., \& Elder, G. H. (1999). Pathways of economic influence on adolescent adjustment. American Journal of Community Psychology, 27, 519-541.

Conger, K. J., Rueter, M. A., \& Conger, R. D. (2000). The role of economic pressure in the lives of parents, their adolescents: The family stress model. In L. J. Crockett \& R. K. Silbereisen (Eds.), Negotiating adolescence in times of social change (pp. 201223). Cambridge: Cambridge University Press.

Danziger, S., \& Johnson, R.C. (2005, winter). Welfare reform: The morning after (pp. 9-15). The Milken Institute Review.

Danziger, S. K., Ananat, E. O., \& Browning, K. G. (2004). Childcare subsidies and the transition from welfare to work. Family Relations, 53, 219-228.

Danziger, S. K., Carlson, M. J., \& Henly, J. R. (2001). Post-welfare employment and psychological well-being. Women \& Health, $32,47-49$.

Danziger, S. K., Corcoran, M., Danziger, S., Heflin, C., Kalil, A., Levine, J., Rosen, D., Seefeldt, K., Siefert, K., \& Tolman, R. (2000). Barriers to employment of welfare recipients. In R. Cherry, \& W. M. Rodgers III (Eds.), Prosperity for all? The economic boom and African Americans. New York: Russell Sage Foundation.

Danziger, S., \& Kalil, A. (2002). Welfare reform: Effects of TANF on family well-being. In R. M. Lerner, F. Jacobs, \& D. Wertlieb (Eds.), Handbook of applied developmental science: Promoting positive child, adolescent, and family development (pp. 395420). Thousand Oaks: Sage.

Danziger, S. K., \& Seefeldt, K. S. (2002). Barriers to employment and the "hard to serve": Implications for services, sanctions, and time limits. Focus, 22, 76-81.

Derogatis, L. R., Lipmann, R. S., Rickels, K., Uhlenhuth, E. H., \& Covi, L. (1974). The Hopkins Symptom Checklist (HSCL): A measure of primary symptom dimensions. In P. Pichot (Ed.), Psychological measurements in psychopharmacology: Vol. 7. Modern problems in pharmacopsychiatry (pp. 79-110). Basel: Karger.

Dooley, D., \& Prause, J. (2002). Mental health and welfare transitions: Depression and alcohol abuse in AFDC women. American Journal of Community Psychology, 30, 787-813.

Elder, G. H., Jr., \& Russell, S. T. (2000). Surmounting life's disadvantage. In L. J. Crockett \& R. K. Silbereisen (Eds.), Negotiating adolescence in times of social change (pp. 17-35). Cambridge: Cambridge University Press.

Gollwitzer, P. M. (1999). Implementation intentions: Strong effects of simple plans. American Psychologist, 54, 493-503.

Gollwitzer, P. M., \& Brandstatter, V. (1997). Implementation intentions and effective goal pursuit. Journal of Personality and Social Psychology, 73, 186-199. 
Gollwitzer, P. M., \& Kinney, R. F. (1989). Effects of deliberative and implemental mind-sets on illusion of control. Journal of Personality and Social Psychology, 56, 531-542.

Gutman, M. A., McKay, J., Ketterlinus, R. D., \& McLellan, A. T. (2003). Potential barriers to work for substance-abusing women on welfare: Findings from the CASAWORKS for families pilot demonstration. Evaluation Review, 27, 681-694.

Gyamfi, P., Brooks-Gunn, J., \& Jackson, A. (2001). Associations between employment and financial and parental stress. Women and Health, 32, 119-135.

Hamilton, G. (2002). Moving people from welfare to work: Lessons from the National Evaluation of Welfare-to-Work Strategies. New York: MDRC.

Haskins, R., \& Offner, P. (2003). May, Achieving compromise on welfare reform reauthorization (Brookings Institution policy brief welfare reform and beyond \#25). Washington: The Brookings Institution.

Holzer, H. J., Stoll, M. A., \& Wissoker, D. (2004). Job performance and retention among welfare recipients. Social Service Review, 78, 343-369.

Hu, L., \& Bentler, P. M. (1999). Cutoff criteria for fit indexes in covariance structure analysis: Conventional criteria versus new alternatives. Structural Equation Modeling, 6, 1-55.

Jackson, A. P. (2000). Maternal self-efficacy and children's influence on stress and parenting among single black mothers in poverty. Journal of Family Issues, 21, 3-16.

Jackson, A. P., Brooks-Gunn, J., Huang, C., \& Glassman, M. (2000). Single mothers in low-wage jobs: Financial strain, parenting, and preschooler's outcomes. Child Development, 71, 1409-1423.

Jackson, A. P., \& Scheines, R. (2005). Single mothers' self-efficacy, parenting in the home environment, and children's development in a two-wave study. Social Work Research, 29, 7-20.

Johnson, R.C., \& Corcoran, M.E. (2003). The road to economic selfsufficiency: Job quality and job transition patterns after welfare reform. Journal of Policy Analysis \& Management, 615-639.

Kalil, A., Schweingruber, H. A., \& Seefeldt, K. S. (2001). Correlates of employment among welfare recipients: Do psychological characteristics and attitudes matter? American Journal of Community Psychology, 29, 701-723.

Kline, R. B. (2005). Principles and practice of structural equation modeling (2nd edn.). New York: The Guilford Press.

Kunz, J., \& Kalil, A. (1999). Self-esteem, self-efficacy, and welfare use. Social Work Research, 23, 119-126.

Lee, S. (2004). Women's work supports, job retention, and job mobility: Child care and employer-provided health insurance help women stay on jobs (Research-in-Brief \#C359). Washington: The Institute for Women's Policy Research.

Lichter, D. T., \& Jayakody, R. (2002). Welfare reform: How do we measure success? Annual Review of Sociology, 28, 117-141.

Lino, M. (1994). Income and spending patterns of single-mother families. Monthly Labor Review, 117(5), 29-37

Loprest, P. (2002a). New federalism national survey of America's families: Who returns to welfare? Washington: The Urban Institute.

Loprest, P. (2002b). Snapshots of America's families III, No. 3: Disconnected welfare leavers face serious risks. Washington: The Urban Institute.

Loprest, P., \& Zedlewski, S. (2006). The changing role of welfare in the lives of low-income families with children (occasional paper \#73). Washington: The Urban Institute.

Meichenbaum, D. (1985). Stress inoculation training: A clinical guidebook. New York: Pergamon.

Michalopoulos, C., Card, D., \& Gennetian, L. A. (2000a). The selfsufficiency program at months: Effects of a financial work incentive on employment and income. Ottawa: Social Research and Demonstration Corp.
Michalopoulos, C., Schwartz, C., \& Adams-Ciardullo, D. (2000b). What works best for whom: Impacts of 20 welfare-to-work programs by subgroup. New York: MDRC.

Miller, C., Knox, V., Gennetian, L. A. et al. (2000). Final report on the Minnesota family investment program. Vol. 1, effects on adults. New York: Manpower Demonstration Research Corp.

Nam, Y. (2005). The roles of employment barriers in welfare exits and reentries after welfare reform: Event history analyses. The Social Service Review, 79, 268-293.

Pavetti, L., Olson, K. K., Pindus, N. M., Pernas, M., \& Isaacs, J. (1996). Designing welfare-to-work program for families facing personal or family challenges. Washington: Urban Institute.

Perlin, L., \& Schooler, C. (1978). The structure of coping. Journal of Health and Social Behavior, 19, 2-21.

Pollack, H. A., Danziger, S., Seefeldt, K. S., \& Jayakody, R. (2002). Substance use among welfare recipients: Trends and policy responses. The Social Service Review, 76, 256-276.

Raykov, T., Tomer, A., \& Nesselroade, J. R. (1991). Reporting structural equation modeling results in Psychology and Aging: Some proposed guidelines. Psychology and Aging, 6 , 499-503.

Raver, C. C. (2003). Does work pay psychologically as well as economically? The role of employment in predicting depressive symptoms and parenting among low-income families. Child Development, 74, 1720-1736.

Sandanger, I., Moum, T., Ingebrigtsen, G., Dalgard, O. S., Sorensen, T., \& Gruusgaard, D. (1998). Concordance between symptom screening and diagnostic procedure: The Hopkins Symptom Checklist-25 and the composite international diagnostic interview. Social Psychiatry and Psychiatric Epidemiology, 33(7), 345-354.

Scarpace, R., Crichton, L. I., \& Meyer, V.A. (2005). Minnesota Family Investment Program longitudinal study: Four years after baseline (10th report in a series). St. Paul, MN: Minnesota Department of Human Services. Available online at: http://www. dhs.state.mn.us.

Taylor, L. C. (2001). Work attitudes, employment barriers, and mental health symptoms in a sample of rural welfare recipients. American Journal of Community Psychology, 29, 443-463.

Taylor, M. J., \& Barusch, A. S. (2004). Personal, family, and multiple barriers of long-term welfare recipients. Social Work, 49, 175-184.

van Ryn, M., \& Vinokur, A. D. (1992). How did it work? An examination of the mechanisms through which a community intervention influenced job-search behavior among an unemployed sample. American Journal of Community Psychology, 5, 577-597.

Vinokur, A., \& Caplan, R. D. (1987). Attitudes and social support: Determinants of job seeking behavior and well-being among the unemployed. Journal of Applied Social Psychology, 17, 1007-1024.

Vinokur, A. D., Price, R. H., \& Schul, Y. (1995). Impact of the JOBS intervention on unemployed workers varying in risk for depression. American Journal of Community Psychology, 23, 39-74.

Vinokur, A. D., \& Schul, Y. (1997). Mastery and inoculation against setbacks as active ingredients in the JOBS intervention for the unemployed. Journal of Consulting and Clinical Psychology, 65, 867-877.

Vinokur, A. D., \& Schul, Y. (2002). The web of coping resources and pathways to reemployment following a job loss. Journal of Occupational Health Psychology, 7, 68-83.

Vinokur, A. D., Schul, Y., Vuori, J., \& Price, R. H. (2000). Two years after a job loss: Long term impact of the JOBS program on reemployment and mental health. Journal of Occupational Health Psychology, 5(1), 32-47. 
Vuori, J., Silvonen, J., Vinokur, A. D., \& Price, R. H. (2002). The Työhön Job Search Program in Finland: Benefits for the unemployed with risk of depression or discouragement. Journal of Occupational Health Psychology, 7, 5-19.

Vuori, J., \& Vinokur, A. D. (2005). Job-search preparedness as a mediator of the effects of the Työhön Job Search Intervention on re-employment and mental health. Journal of Organizational Behavior, 26, 275-291.

Zedlewski, S. R. (2003). Snapshots of America's families III, No. 3: Work and barriers to work among welfare recipients in 2002. Washington: The Urban Institute. 